\title{
Desempenho de novilhos alimentados com rações contendo silagem de capim papuã (Urochloa plantaginea) x silagem de sorgo (Sorghum bicolor (L.) Moench)
}

\section{Steers performance fed diets with Alexander grass silage (Urochloa plantaginea) x sorghum silage (Sorghum bicolor (L.) Moench)}

\author{
Flânia Mônego Argenta ${ }^{1 *}$; Ivan Luiz Brondani²; Dari Celestino Alves Filho³; \\ João Restle ${ }^{4}$; Luciane Rumpel Segabinazzi ${ }^{5}$; Jonatas Cattelam ${ }^{6}$;
}

Viviane Santos da Silva ${ }^{1}$; Perla Cordeiro de Paula ${ }^{1}$; Ricardo Lima de Azevedo Júnior ${ }^{1}$; John Lenon Klein ${ }^{7}$; Sander Martinho Adams ${ }^{7}$; Odilene de Souza Teixeira ${ }^{7}$

\begin{abstract}
Resumo
Este trabalho foi realizado com o objetivo de avaliar o desempenho de novilhos de corte terminados em confinamento, alimentados com silagem de capim papuã ou silagem de sorgo, como fonte de volumoso através de alguns parâmetros de alimentação. Foram utilizados 12 animais com peso e idade média inicial de $245 \mathrm{~kg}$ e 20 meses, respectivamente, pertencentes aos grupos genéticos Nelore (N), Charolês (C), ${ }^{21} /{ }_{32} \mathrm{~N}^{11}{ }_{32} \mathrm{C},{ }_{32}{ }_{32} \mathrm{C}^{11}{ }_{32} \mathrm{~N} ;{ }^{43} /{ }_{64} \mathrm{~N}^{21 /}{ }_{64} \mathrm{C} \mathrm{e}{ }^{43} /{ }_{64} \mathrm{C}^{21 /}{ }_{64} \mathrm{~N}$. A ração foi composta por uma relação volumoso:concentrado de 50:50 (base na matéria seca), ofertada à vontade. O consumo diário de matéria seca; proteína bruta; extrato etéreo; fibra em detergente neutro e fibra em detergente ácido não diferiram entre as fontes de volumosos, sendo os valores médios de 10,18; 1,28; 0,20;4,96 e 2,51 kg/ dia, respectivamente. No entanto, o consumo de extrato etéreo por tamanho metabólico e por percentual de peso corporal foram maiores para os que consumiram silagem de sorgo, obtendo valores de 2,74 e 2,36 g/tamanho metabólico e 0,06 e $0,05 \mathrm{~kg} / 100 \mathrm{~kg}$ de peso vivo. Mesmo comportamento foi observado para o consumo de energia digestível, apresentando valores de 346,87 e 302,83 g/tamanho metabólico e 8,10 e $7,02 \mathrm{~kg} / 100 \mathrm{~kg}$ de peso vivo. O ganho médio diário, escore corporal final e a conversão alimentar não foram influenciados pelo tipo de volumoso, sendo os valores médios de 1,31 kg; 4,05 pontos e 7,78 $\mathrm{kg}$ de $\mathrm{MS} / \mathrm{kg}$ de ganho de peso, respectivamente. A silagem de capim papuã é uma alternativa viável quanto a sua substituição em relação à silagem de sorgo.
\end{abstract}

Palavras-chave: Conversão alimentar, consumo de matéria seca, extrato etéreo, ganho médio diário

\footnotetext{
${ }^{1}$ Zootecnistas, Discentes do Curso de Mestrado em Zootecnia, Universidade Federal de Santa Maria, RS. Bolsistas CAPES. E-mail: flaniama@yahoo.com.br; stsvivi@gmail.com; perla.zoot@gmail.com; ricardo.junior@zootecnista.com.br

${ }^{2}$ Zootecnista, Prof. Dr. Associado do Dept ${ }^{\circ}$ de Zootecnia, UFSM, RS. Bolsista CNPq. Bolsista CNPq. E-mail: ivanbrondani@ gmail.com

${ }^{3}$ Eng $^{\mathrm{o}} \mathrm{Agr}^{\circ}$, Prof. Dr. Adjunto do Dept ${ }^{\circ}$ de Zootecnia, UFSM, RS. Bolsista do CNPq. E-mail: darialvesfilho@hotmail.com

${ }^{4}$ Eng $^{\mathrm{o}}$ Agr $^{\mathrm{o}}, \mathrm{PhD}$, Prof. da UFT, Campus Araguaína, TO. E-mail: jorestle@terra.com.br

${ }^{5}$ Zootecnista, Prof ${ }^{a}$ Dr $^{\mathrm{a}}$ Adjunta da Universidade do Pampa, UNIPAMPA, RS. E-mail: lucianesegabinazzi@unipampa.edu.br

${ }^{6}$ Médico Veterinário, Discente do Curso de Mestrado em Zootecnia, UFSM, RS. Bolsista CAPES. E-mail: jonatascattelam@, yahoo.com.br

${ }^{7}$ Discentes de Graduação em Zootecnia, UFSM, RS. E-mail: johnlenomklein@yahoo.com.br; sander.adams@hotmail.com; odilene_rs@hotmail.com

* Autor para correspondência
} 


\begin{abstract}
This study aimed to evaluate the parameters related to feedlot beef steers fed with Alexander grass silage or sorghum silage as roughage source. Twelve animals with initial average of weight and age of $245 \mathrm{~kg}$ and 20 months, respectively, belonging to Nellore (N), Charolais (C), ${ }_{32}^{21} \mathrm{~N}^{11} /{ }_{32} \mathrm{C}^{21} /{ }_{32} \mathrm{C}^{11} /{ }_{32} \mathrm{~N} ;{ }_{64}^{43} \mathrm{~N}$ ${ }^{21} /{ }_{64} \mathrm{C}$ and ${ }^{43} /{ }_{64} \mathrm{C} 21 /{ }_{64} \mathrm{~N}$ genetic groups were used. The ration was composed by a roughage:concentrate relation of 50:50 (dry matter basis), offered at ease. The dry matter, crude protein, ether extract, neutral detergent fiber and acid detergent fiber daily intake didn't differ between roughage sources, being the medium values of $10.18 ; 1.28 ; 0.20 ; 4.96$ and $2.51 \mathrm{~kg} /$ day, respectively. However, the ether extract intake by metabolic size and by corporal weight percentage were higher for the one that consumed sorghum silage, obtaining values of 2.74 and $2.36 \mathrm{~g} /$ metabolic size and 0.06 and $0.05 \mathrm{~kg} / 100 \mathrm{~kg}$ of live weight. The same behavior was observed for digestible energy intake, presenting values of 364.87 and $302.83 \mathrm{~g} / \mathrm{metabolic}$ size and 8.10 and $7.02 \mathrm{~kg} / 100 \mathrm{~kg}$ of live weight. The daily average gain, final corporal score and feed conversion weren't influenced by roughage type, being the values of $1.31 \mathrm{~kg}$; 4.05 points and $7.78 \mathrm{~kg}$ of DM/ $\mathrm{kg}$ of weight gain, respectively. The Alexander grass silage is a feasible alternative as its substitution in relation to sorghum silage.
\end{abstract}

Key words: Daily average gain, dry matter intake, ether extract, feed conversion

\section{Introdução}

Diante do cenário atual da pecuária de corte, o Brasil detém o maior rebanho comercial do mundo. Segundo dados do Anualpec (2010), representam aproximadamente 200 milhões de cabeças, sendo a produção tanto a pasto e confinamento. Nos últimos anos vem ocorrendo expressivo aumento de sistema de terminação em confinamento, o qual aproximadamente $7,39 \%$ dos bovinos terminados são resultantes desse sistema de terminação (ANUALPEC, 2010). No entanto, o confinamento apresenta algumas desvantagens quanto ao custo de alimentação. De acordo com Pacheco et al. (2006), em sistemas de confinamento, excluindo os animais, a alimentação pode representar cerca de $73,9 \%$ do custo. Dessa forma, torna-se importante a tomada de decisão na hora do planejamento, levando em conta a disponibilidade e o custo da matéria prima para minimizar os custos de produção.

As forrageiras de maior destaque na produção de silagens são o milho e o sorgo, ambas com alto valor nutritivo, no entanto, embora com produção e qualidade semelhantes, o sorgo torna-se mais rústico frente ao milho quanto aos problemas de estresse hídrico, pragas e invasoras, os quais acarretam diminuição na produção e qualidade da silagem. Diante do pressuposto, alternativa para a produção de silagem é o capim papuã (Urochloa plantaginea), uma planta com grande aceitação pelos animais na forma verde, porém pouco difundida, por ser uma invasora muita conhecida na região sul do Brasil. O capim papuã possui alta relação folha:caule no período inicial do seu ciclo, além de ser uma espécie sem custo de implantação, uma vez que, por ser uma invasora de lavouras de verão, surge como alternativa na alimentação na forma de silagem para bovinos.

Dessa forma, este trabalho tem por objetivo de avaliar o desempenho de novilhos terminados em confinamento, alimentados com rações contendo silagem de capim papuã, como alternativa de volumoso.

\section{Material e Métodos}

O experimento foi conduzido no Laboratório de Bovinocultura de Corte do Departamento de Zootecnia da Universidade Federal de Santa Maria (UFSM). O local encontra-se na região fisiográfica denominada Depressão Central e apresenta como coordenadas $29^{\circ}$ e $43^{\prime}$ de Latitude Sul e $53^{\circ}$ e $42^{\prime}$ de Longitude Oeste. O clima da região é o Cfa (subtropical úmido), conforme classificação de Köppen. 
Foram utilizados 12 novilhos castrados, produtos do cruzamento alternado rotativo das raças Charolês e Nelore realizado no rebanho experimental do Departamento de Zootecnia da UFSM. Os animais pertenciam aos grupos genéticos Nelore (N), Charolês (C), ${ }^{21 /}{ }_{32} \mathrm{~N} \mathrm{11/}{ }_{32} \mathrm{C}, 21 /{ }_{32} \mathrm{C} 11 / 32 \mathrm{~N}, 43 /{ }_{64} \mathrm{~N}$ ${ }^{21 /}{ }_{64} \mathrm{C} \mathrm{e} 43 /{ }_{64} \mathrm{C} 21 /{ }_{64} \mathrm{~N}$, e apresentavam peso vivo e idade média inicial de $245 \mathrm{~kg}$ e 20 meses de idade, respectivamente.

Os animais permaneceram em baias individuais de $20 \mathrm{~m}^{2}$, semi-cobertas e piso em concreto armado, sendo os comedouros individuais e os bebedouros comuns a cada duas baias. Os animais foram submetidos a dois tratamentos alimentares os quais diferiram quanto ao tipo de volumoso, sendo a silagem de papuã e a silagem de sorgo, ambas com relação volumoso:concentrado 50:50 (com base na matéria seca).

O período de confinamento foi de 170 e 136 dias para os animais que consumiram silagem de papuã e silagem de sorgo, respectivamente, de modo que o critério de abate foi o peso corporal de $430 \mathrm{~kg}$. Antecedendo o período experimental, os animais foram submetidos a um período de adaptação às instalações, manejo e às dietas experimentais, por 15 dias. No início da adaptação, os animais foram vermifugados com produto à base de sulfóxido de albendazol, para controle de endoparasitas.

As rações isoprotéicas foram formuladas de forma para atender asas exigências nutricionais dos animais, objetivando ganho de peso médio diário (GMD) de 1,2 kg/animal com consumo estimado de matéria seca de $2,5 \mathrm{~kg} / 100 \mathrm{~kg}$ de peso vivo. Os ingredientes do concentrado utilizados para a dieta foram o farelo de trigo, farelo de soja, milho moído, cloreto de sódio $(\mathrm{NaCl})$, calcário calcítico e uréia. A análise bromatológica dos ingredientes está apresentada na Tabela 1. A ração ofertada aos animais foi "ad libitum", fornecida em duas refeições diárias (8:00 e 14:00 h), sendo as sobras pesadas e ajustadas diariamente de modo que oscilassem entre 5 e $8 \%$ do total de alimento ofertado. O volumoso composto pela silagem de papuã e de sorgo foi distribuído no comedouro e posteriormente o concentrado, onde foi realizada mistura manual e homogênea para que os animais ingerissem a ração de forma proporcional.

Tabela 1. Composição bromatológica dos ingredientes das dietas.

\begin{tabular}{|c|c|c|c|c|c|c|c|c|}
\hline \multirow{3}{*}{ Teores } & \multicolumn{2}{|c|}{ Silagem } & \multicolumn{2}{|c|}{ Farelo } & \multirow{2}{*}{$\begin{array}{l}\text { Milho } \\
\text { Grão }\end{array}$} & \multirow{2}{*}{$\begin{array}{l}\text { Calcário } \\
\text { Calcítico }\end{array}$} & \multirow{2}{*}{$\begin{array}{l}\text { Cloreto } \\
\text { de Sódio }\end{array}$} & \multirow{2}{*}{ Uréia } \\
\hline & Papuã & Sorgo & Trigo & Soja & & & & \\
\hline & \multicolumn{8}{|c|}{$\mathrm{g} / \mathrm{kg}$} \\
\hline $\mathrm{MS}^{1}$ & 286,8 & 305,6 & 828,6 & 903,6 & 879,5 & $1.000,0$ & $1.000,0$ & - \\
\hline $\mathrm{MO}^{2}$ & 894,3 & 909,4 & 953,7 & 929,3 & 987,7 & 736,7 & - & - \\
\hline $\mathrm{MM}^{2}$ & 105,7 & 90,6 & 46,3 & 70,7 & 12,3 & 363,3 & $1.000,0$ & - \\
\hline $\mathrm{PB}^{2}$ & 69,5 & 54,6 & 189,4 & 496,7 & 100,4 & - & - & 281 \\
\hline $\mathrm{EE}^{2}$ & 8,1 & 8,0 & 34,6 & 23,0 & 32,4 & - & - & - \\
\hline FDA $^{2}$ & 447,2 & 420,0 & 163,1 & 95,4 & 41,4 & - & - & - \\
\hline $\mathrm{FDN}^{2}$ & 778,8 & 651,3 & 520,1 & 173,1 & 186,7 & - & - & - \\
\hline $\mathrm{NIDN}^{2}$ & 4,7 & 3,4 & 7,8 & 6,0 & 3,8 & - & - & - \\
\hline $\mathrm{NIDA}^{2}$ & 2,7 & 2,1 & 1,7 & 1,8 & 0,8 & - & - & - \\
\hline $\mathrm{LDA}^{2}$ & 74,7 & 55,6 & 48,3 & 11,7 & 10,2 & - & - & - \\
\hline $\mathrm{NDT}^{2}$ & 452,6 & 541,2 & 635,7 & 775,9 & 854,7 & - & - & - \\
\hline
\end{tabular}

${ }^{1} \mathrm{MS}$ : matéria seca (g/kg de matéria natural)

${ }^{2} \mathrm{MO}$ : matéria orgânica, MM: matéria mineral, PB: proteína bruta, EE: extrato etéreo, FDA: fibra em detergente ácido, FDN: fibra em detergente neutro, NIDN: nitrogênio insolúvel em detergente neutro, NIDA: nitrogênio insolúvel em detergente ácido, LDA: lignina em detergente ácido, NDT: nutrientes digestíveis totais.

Fonte: Elaboração dos autores. 
Durante o período experimental, duas vezes por semana foram coletadas amostras representativas das rações fornecidas aos animais (concentrados e volumosos), com intuito de realizar posteriormente análise bromatológica da ração. Além disso, periodicamente, amostras dos ingredientes do concentrado também foram coletadas para serem analisadas. As amostras da ração foram pré-secas em estufa com circulação forçada de ar a $55 \pm 5^{\circ} \mathrm{C}$, por 72 horas para determinação do teor de matéria parcialmente seca. Após a pré secagem, foram processadas em moinho tipo willey com peneira com crivos de $1 \mathrm{~mm}$ de diâmetro e posteriormente armazenadas para análises bromatológicas, realizadas no Núcleo Integrado de Desenvolvimento em Análises Laboratoriais (NIDAL) da Universidade Federal de Santa Maria.

Foram determinados os teores de matéria seca (MS) em estufa a $105^{\circ} \mathrm{C}$ por período de 16 horas. $\mathrm{O}$ conteúdo de cinzas foi determinado por calcinagem em mufla à temperatura de $550^{\circ} \mathrm{C}$ durante 2 horas. $\mathrm{O}$ teor de matéria orgânica (MO) foi estimado pela diferença entre a MS e cinzas. As análises de matéria seca (MS), matéria orgânica (MO), matéria mineral (MM), proteína bruta (PB) e extrato etéreo (EE), foram determinados conforme metodologias propostas pelo AOAC (1995).

Os teores de lignina em detergente ácido (LDA), fibra insolúvel em detergente neutro (FDN) e fibra insolúvel em detergente ácido (FDA) foram efetuadas conforme Van Soest et al. (1991). O Nitrogênio insolúvel em detergente ácido (NIDA), nitrogênio insolúvel em detergente neutro (NIDN), foram analisados de acordo com a metodologia descrita por Licitra, Hernandez e Van Soest (1996). $\mathrm{O}$ teor de nutrientes digestíveis totais (NDT) foi analisado conforme Weiss, Conrad e St. Pierre (1992). Esses valores foram determinados para as diferentes dietas pela equação:

$$
\mathrm{NDT}=\mathrm{PBD}+\mathrm{EED} \times 2,25+\mathrm{FDND}+\mathrm{CNFD}
$$

em que PBD = proteína bruta digestível; EED $=$ extrato etéreo digestível; FDND $=$ fibra em detergente neutro digestível; CNFD = carboidratos não-fibrosos digestível.

A energia digestível (ED) foi calculada segundo NRC (1996), em que $1 \mathrm{~kg}$ de NDT=4,4 Mcal de ED. A participação dos ingredientes e os valores da composição bromatológica das rações experimentais são apresentados na (Tabela 2).

Tabela 2. Participação dos ingredientes (base na MS) e composição bromatológica das dietas experimentais.

\begin{tabular}{lcc}
\hline \multirow{2}{*}{\multicolumn{1}{c}{ Ingredientes, \% }} & \multicolumn{2}{c}{ Tipos de Silagem } \\
\cline { 2 - 3 } & Papuã & Sorgo \\
\hline Silagem de papuã & \multicolumn{1}{c}{53} & \multicolumn{1}{c}{-} \\
Silagem de sorgo & 21,2 & 23,55 \\
Farelo de trigo & 20,20 & 19,50 \\
Milho grão & 3,75 & 3,90 \\
Farelo de soja & 1,15 & 1,20 \\
Calcário Calcítico & 0,20 & 0,25 \\
Cloreto de sódio & 0,50 & 0,60 \\
Uréia & \multicolumn{2}{|}{} \\
\hline Composição Bromatológica, \% & 42,44 & 57,83 \\
\hline Matéria seca & 12,99 & 12,83 \\
Proteína Bruta & 1,90 & 2,10 \\
Extrato Etéreo & 7,10 & 6,23 \\
Matéria Mineral & 28,35 & 26,44 \\
Fibra em detergente ácido & 56,72 & 49,78 \\
Fibra em detergente neutro & 5,24 & 4,22 \\
Lignina & 57,64 & 62,26 \\
Nutrientes digestíveis totais & 25,40 & 26,90 \\
Energia Digestível, Mcal/kg de MS
\end{tabular}

Fonte: Elaboração dos autores.

Foi avaliada a degradabilidade ruminal de cada componente de forma individual das dietas, nas quais incluiu-se farelo de trigo, farelo de soja, grão de milho moído, silagem de capim papuã e silagem de sorgo. Aproximadamente $0,5 \mathrm{~g}$ de amostra seca em estufa com circulação forçada de ar a $55^{\circ} \mathrm{C}$ e moída (peneira de $1 \mathrm{~mm}$ ) de cada componente da dieta foi pesado em sacos filtro de poliéster $(5 \times 5 \mathrm{~cm}$; porosidade de $50 \mu \mathrm{m}$ ) e incubadas no rúmen de um novilho fistulado durante 48 horas. Posteriormente, as amostras foram retiradas do rúmen, e os sacos contendo o resíduo da incubação foram lavados com 
água corrente e, sequencialmente, o resíduo tratado com solução detergente neutro em autoclave à $110^{\circ}$ C por 40 minutos (SENGER et al., 2008). Para a obtenção dos valores de degradabilidade ruminal da MS, após o tratamento com solução detergente neutro, as amostras foram secas em estufa a $110^{\circ} \mathrm{C}$ por 12 horas. A degradabilidade ruminal da matéria orgânica foi obtida pela combustão do resíduo das dietas incubadas em mufla a $600^{\circ} \mathrm{C}$ durante quatro horas. Os valores da degradabilidade ruminal das dietas estão apresentados na Tabela 3.

Tabela 3. Degradabilidade ruminal "in situ" da silagem e dos ingredientes do concentrado.

\begin{tabular}{lcc}
\hline \multirow{1}{*}{\multicolumn{1}{c}{ Item }} & \multicolumn{2}{c}{ Degradabilidade Ruminal } \\
\cline { 2 - 3 } & $\begin{array}{c}\text { Matéria seca, } \\
\%\end{array}$ & $\begin{array}{c}\text { Matéria } \\
\text { orgânica, \% }\end{array}$ \\
\hline Farelo de trigo & 70,17 & 69,36 \\
Farelo de soja & 97,21 & 96,68 \\
Milho moído & 95,99 & 96,05 \\
Silagem de Papuã & 48,79 & 46,33 \\
Silagem de Sorgo & 51,67 & 49,61 \\
\hline
\end{tabular}

Fonte: Elaboração dos autores.

O delineamento experimental utilizado para o desempenho animal foi blocos ao acaso com dois tratamentos e seis repetições, sendo o animal a unidade experimental. Os dados foram testados quanto à normalidade, através do teste de ShapiroWilk com $\alpha=0,05$. Os dados foram submetidos à análise de variância e teste F, pelo PROC GLM e as médias comparadas através do teste " $\mathrm{t}$ " de Student, a $\alpha=0,05$ de probabilidade utilizando o pacote estatístico SAS (Statistical Analysis System, versão 9.2). Os dados da variável consumo de MS por tamanho metabólico (CMSTM) foram analisadas após a transformação raiz quadrada. O modelo matemático para as todas variáveis foi o seguinte:

$Y i j=\mu+\tau i+\beta j+\varepsilon i j$, em que:

Yij = variáveis dependentes; $\mu=$ média de todas as observações; $\tau \mathrm{i}=$ efeito do i-ésimo tratamento; $\beta \mathrm{j}=\mathrm{o}$ efeito do j-ésimo bloco; e cij = erro aleatório residual.

\section{Resultados e Discussão}

As diferentes fontes de volumoso, silagem de papuã ou silagem de sorgo, não interferiram $(\mathrm{P}>0,05)$ no consumo de MS pelos animais, independentemente da forma como foi expresso (Tabela 4), associado à semelhança na relação volumoso:concentrado na dieta dos novilhos. Ao estudar o desempenho de bezerros de corte em confinamento, alimentados com dietas contendo diferentes fontes de volumoso com ou sem inoculantes, Restle et al. (2003), não verificaram diferença significativa entre o uso de silagem de capim papuã com ou sem inoculante, ou com a mistura de silagem de milho e silagem de sorgo, em rações com a mesma relação volumoso:concentrado usado no presente experimento, demonstrando que o uso de inoculante bacteriano na silagem de papuã, não promoveu melhorias no desempenho animal.

Tabela 4. Consumos de matéria seca e proteína bruta de novilhos alimentados com diferentes tipos de volumoso.

\begin{tabular}{|c|c|c|c|c|}
\hline \multirow{2}{*}{ Consumos } & \multicolumn{2}{|c|}{ Tipos de Silagem } & \multirow{2}{*}{ Erro- padrão } & \multirow{2}{*}{ Probabilidade } \\
\hline & Papuã & Sorgo & & \\
\hline Matéria seca, $\mathrm{kg} / \mathrm{dia}$ & 9,89 & 10,48 & 0,735 & 0,5969 \\
\hline Matéria seca, g/tamanho metabólico & 122,66 & 132,57 & 4,312 & 0,1652 \\
\hline Matéria seca, $\mathrm{kg} / 100 \mathrm{~kg}$ de peso vivo & 2,84 & 2,93 & 0,114 & 0,6262 \\
\hline Proteína Bruta, kg/dia & 1,27 & 1,30 & 0,088 & 0,8125 \\
\hline Proteína Bruta, g/tamanho metabólico & 15,72 & 16,44 & 0,527 & 0,3797 \\
\hline Proteína Bruta, $\mathrm{kg} / 100 \mathrm{~kg}$ de peso vivo & 0,36 & 0,38 & 0,009 & 0,1861 \\
\hline
\end{tabular}

Fonte: Elaboração dos autores. 
Ao realizar análise de contraste entre as dietas que incluíam silagem de capim papuã (com e sem inoculante) contra a que incluía a mistura de silagem de milho e sorgo Restle et al. (2003), relataram que os animais alimentados com silagem de capim papuã apresentaram menor consumo de matéria seca $(4,99 \mathrm{~kg} /$ dia contra $5,56 \mathrm{~kg} /$ dia $)$ sem diferença para o consumo em percentagem de peso vivo e por unidade de tamanho metabólico.

Ao contrastar os resultados do presente trabalho com o realizado por Restle et al. (2003) verifica-se que quando se trabalha com diferentes categorias, o consumo de MS pode ser influenciado pelo grau de distensão ruminal ou saciedade energética. Segundo os autores Balch e Campling (1962) e Mertens (1994), quando os animais são submetidos a dietas fibrosas, que apresentam maior volume e reduzida concentração energética, o consumo apresenta limitação física, ou seja, devido à distensão ruminal decorrente da alta ingestão de alimentos fibrosos, diminuindo assim, o consumo de MS.

Porém, Mertens (1994), relatou que o consumo também pode ser regulado a partir da demanda energética do animal, que ocorre quando estes são alimentados com dietas com alta concentração energética e com alta digestibilidade. Nesse caso, a reduzida capacidade de enchimento do rúmen não causa distensão ruminal e o consumo é limitado pelo atendimento das exigências energética do animal.

A saciedade pode ser um fator fisiológico limitante do consumo para dietas com elevada densidade calórica, neste caso, as exigências do animal controlariam o consumo, como em condições de confinamento (CABRAL et al., 2006). Estes autores relataram que os fatores físicos predominam em dietas com baixa qualidade nutritiva, em que o consumo é limitado pelo volume ocupado pela ração e pela capacidade anatômica do rúmen-retículo, de modo que, raramente, os animais ingerem energia suficiente para atender seus requisitos, o que geralmente ocorre com animais em pastejo.
Outro fator que interfere no consumo de MS é o teor de lignina (Tabela 2), influenciando de forma negativa no consumo. No presente estudo, foram observados que para cada $\mathrm{kg}$ da silagem de papuã o teor de lignina aumentava 10,2 g em relação à silagem de sorgo. A diferença no teor de lignina teve influência negativa no consumo de MS dos animais em 0,42 kg de MS/dia $(\mathrm{P}<0,05)$, interferindo no ganho médio diário que apresentou diferença de $0,100 \mathrm{~kg} /$ dia entre os tratamentos, levando os animais alimentados com a silagem e papuã permanecerem confinados por mais 34 dias. Diante disso, o consumo e a quantidade de lignina no alimento ofertado tornam-se fundamental à nutrição, pois determina o nível de nutrientes ingeridos e, portanto, a resposta animal (VAN SOEST, 1994).

$\mathrm{O}$ consumo de proteína bruta $(\mathrm{PB})$ nas diferentes formas de expressar, não foi influenciado $(\mathrm{P}<0,05)$ pelos tratamentos. $O$ consumo de $\mathrm{PB}$ para o tratamento silagem de papuã apresentou consumo de $1,27 \mathrm{~kg} /$ dia, enquanto a silagem de sorgo obteve $1,30 \mathrm{~kg} / \mathrm{dia}$ de consumo de PB. A similaridade no consumo de $\mathrm{PB}$ está relacionada às dietas serem isonitrogenadas (Tabela 2), além da igualdade no consumo de MS.

A concentração e a qualidade da proteína da dieta podem alterar tanto o mecanismo físico como o quimiostático do consumo nos ruminantes (ARAÚJO et al., 1998). Redução na proteína da dieta abaixo de $120 \mathrm{~g} / \mathrm{kg}$ de MS ou diminuição da disponibilidade de nitrogênio poderá reduzir a digestão da fibra, uma vez que restringe o desenvolvimento da flora microbiana, e reduz o consumo em consequência da lenta passagem dos alimentos pelo rúmen. (ARAÚJO et al., 1998).

No que se refere ao consumo de extrato etéreo (EE) da dieta (Tabela 5), foi verificado diferença significativa em relação ao peso metabólico e por $\mathrm{kg} / 100 \mathrm{~kg}$ de peso vivo. Desse modo, os animais que consumiram silagem de sorgo obtiveram médias superiores (2,74 g de EE/ tamanho metabólico) 
quando comparado aos que consumiram silagem de papuã (2,36 g de EE/ tamanho metabólico).

Em relação ao consumo de energia digestível (CED) (Tabela 5), houve diferença significativa quando expresso em peso corporal metabólico e por $\mathrm{kg} / 100 \mathrm{~kg}$ de peso vivo. Os animais que consumiram silagem de sorgo apresentaram valores superiores (346,87 g/tamanho metabólico e 8,10 $\mathrm{kg} / 100 \mathrm{~kg}$ de peso vivo), quando comparado aos animais do tratamento papuã $(302,83 \mathrm{~g} /$ tamanho metabólico e 7,02 kg/100 kg de peso vivo), respectivamente para tais variáveis. Geralmente a silagem de sorgo apresenta maior concentração de grãos na massa ensilada, obtendo maior teor de energia, possibilitando maior digestibilidade e aproveitamento dos nutrientes, com isso, elevando o CED.

Tabela 5. Consumos diários de extrato etéreo e energia digestível de novilhos alimentados com diferentes tipos de volumoso.

\begin{tabular}{lrrrc}
\hline \multirow{2}{*}{ Consumos } & \multicolumn{2}{c}{ Tipos de Silagem } & \multirow{2}{*}{ Erro-padrão } & \multirow{2}{*}{ Probabilidade } \\
\cline { 2 - 3 } & Papuã & Sorgo & & \\
\hline Extrato etéreo, $\mathrm{kg} / \mathrm{dia}$ & 0,19 & 0,21 & 0,014 & 0,2409 \\
Extrato etéreo, $\mathrm{g} / \mathrm{tamanho}$ metabólico & 2,36 & 2,74 & 0,085 & 0,0246 \\
Extrato etéreo, $\mathrm{kg} / 100 \mathrm{~kg}$ peso vivo & 0,05 & 0,06 & 0,001 & 0,0066 \\
Energia digestível, Mcal/dia & 24,40 & 27,39 & 1,841 & 0,3035 \\
En. digestível, Mcal/tamanho metabólico & 302,83 & 346,87 & 11,345 & 0,0406 \\
Energia Digestível, $\mathrm{kg} / 100 \mathrm{~kg}$ peso vivo & 7,02 & 8,10 & 0,196 & 0,0118 \\
\hline
\end{tabular}

Fonte: Elaboração dos autores.

Não observou diferença no consumo de FDN (Tabela 6), nas diferentes formas de expressar, resultando em valores médios de 4,96 kg/dia, 62,16 $\mathrm{g} /$ tamanho metabólico e $1,45 \mathrm{~kg} / 100 \mathrm{~kg}$ de peso vivo. Contudo, ressalta-se que os teores de FDN para o tratamento silagem de papuã e silagem de sorgo apresentaram 567,2 e 497,8 g/kg de MS, respectivamente. Segundo Van Soest (1994), elevados teores de FDN interferem no consumo e na digestibilidade da MS, no qual, valores superiores a 550-600 g/kg de FDN correlacionamse negativamente com o consumo de MS.
O teor de FDN é um fator que está relacionado com o espaço ocupado pelo alimento no rúmen, principalmente quando a ração consiste, basicamente, em forragens frescas ou picadas grosseiramente (Van Soest, 1994). De acordo com os autores (FORBES, 1995 e CHILIBROSTE et al., 2000), a utilização de forrageiras com baixa qualidade, apresentando teores superiores a $600 \mathrm{~g} /$ $\mathrm{kg}$ de FDN da MS, em condições de corte ou de pastejo, acarreta em aumento do enchimento do rúmen, ocasionado pela menor taxa de passagem de partículas, conseqüentemente ocorre a redução do consumo de MS. 
Tabela 6. Consumos diários de fibra em detergente neutro e fibra em detergente ácido de novilhos alimentados com diferentes tipos de volumoso.

\begin{tabular}{lcccc}
\hline \multirow{2}{*}{ Consumos de Fibra em Detergente } & \multicolumn{2}{c}{ Tipos de Silagem } & \multirow{2}{*}{ Erro-padrão } & \multirow{2}{*}{ Probabilidade } \\
\cline { 2 - 3 } & Papuã & Sorgo & & \\
\hline Neutro, kg/dia & 5,21 & 4,71 & 0,380 & 0,3903 \\
Neutro, g/ tamanho metabólico & 64,73 & 59,6 & 2,459 & 0,2004 \\
Neutro, kg/100 kg de peso vivo & 1,51 & 1,39 & 0,042 & 0,1272 \\
Ácido, kg/dia & 2,56 & 2,46 & 0,188 & 0,6846 \\
Ácido, g/tamanho metabólico & 32,02 & 31,19 & 1,190 & 0,6438 \\
Ácido, kg/100 kg de peso vivo & 0,74 & 0,73 & 0,020 & 0,6363 \\
\hline
\end{tabular}

Fonte: Elaboração dos autores.

Segundo Mertens (1982), quando a fração de FDN é baixa, ou seja, fração fibrosa é pequena, a ingestão será controlada pela exigência energética pelo animal, através da saciedade. Entretanto, quando a fração fibrosa é alta, o animal necessita ingerir mais alimento para atender suas exigências energéticas, ou seja, sua ingestão será controlada pela capacidade física do rúmen.

Em vacas em lactação Mertens (1992) observou que a ingestão foi inferior a $1,2 \mathrm{~kg} / 100 \mathrm{~kg}$ de peso vivo de FDN na ração fornecida. Madsen, Hvelpund e Weisbjerg (1997) sugerem que para o consumo de forrageiras tropicais, o consumo de FDN de 1,1 $\mathrm{kg} / 100 \mathrm{~kg}$ de peso vivo, já ocorre o enchimento físico do rúmen. Perante essas informações, todos os tratamentos ficaram fora do desvio padrão sugerido pelo autor para o consumo de FDN, apresentando valores de $1,51 \mathrm{~kg} / 100 \mathrm{~kg}$ de peso vivo para os animais que consumiram silagem de papuã e 1,39 $\mathrm{kg} / 100 \mathrm{~kg}$ de peso vivo para os que consumiram silagem de sorgo.

Diante desses resultados, pode-se inferir que o enchimento físico do rúmen ocorre com percentagens de FDN mais elevadas em relação ao peso do animal. No entanto, a qualidade da forragem pode influenciar o consumo e o fornecimento do alimento para os animais. Em forrageiras tropicais, a maturidade dos tecidos da planta é mais rápida, quando comparada a outros tipos de forrageiras, segundo Moore (1980), com essa rápida maturação, ocorre o aumento da lignificação da parede celular e conseqüentemente reduzirá sua utilização pelos microorganismos.

Chizzotti et al. (2005) trabalharam com novilhos Nelore recebendo dietas contendo silagens de capim-braquiarão e de sorgo nas proporções volumoso:concentrado de 100:0, 67:33, 33:67 e 0:100, e não observaram, no entanto, efeito dos teores de silagem de sorgo sobre os consumos de FDN, expressos em kg/dia e em kg/100 kg de peso vivo, registrando-se valores médios de 3,63 e 0,88 , respectivamente. Por outro lado, Hussein, Merchen e Fahey Júnior (1995) trabalharam com duas relações de volumoso:concentrado (30:70 e 70:30) observaram diferença para o consumo de FDN (305,0 e 413,0 g/kg de MS) respectivamente.

No presente trabalho, ressalta-se que o teor de MS da silagem de papuã e de sorgo foi de 286,8 $\mathrm{g} / \mathrm{kg}$ de MS e 305,6 g/kg de MS, respectivamente. Segundo McDonald (1981), para obter silagem com boa qualidade, o teor de MS da forragem deve variar entre 300 e $350 \mathrm{~g} / \mathrm{kg}$ de MS, pois valores inferiores a $300 \mathrm{~g} / \mathrm{kg}$ de MS podem ocasionar o crescimento de bactérias do gênero Clostridium que realizam proteólise e promove fermentações butíricas que são indesejáveis para se produzir uma silagem de boa qualidade.

Com relação ao consumo de fibra em detergente ácido (FDA), essa não diferiu (Tabela 6) entre os tratamentos nas diferentes formas expressadas. Ítavo et al. (2002) trabalhando com novilhos 
alimentados com dietas contendo vários teores de concentrado (200, 400, 600 e $800 \mathrm{~g} / \mathrm{kg}$ de MS) observaram mudanças para o consumo de FDA, ocorrendo redução no teor de FDA com o aumento de concentrado, conseqüentemente ocorreu redução para os teores de FDN, por serem proporcionais. Por outro lado, Araújo et al. (1998) testaram diferentes teores de volumoso na alimentação de bezerros (100, 250, 400, 550 e $900 \mathrm{~g} / \mathrm{kg}$ de MS) e observaram aumento no consumo de FDA à medida que a proporção de volumoso foi crescendo na dieta dos bezerros.

Chizzotti et al. (2005) estudaram o desempenho de novilhos Nelore recebendo rações com teores crescentes de silagem de sorgo $(0,330,670$ e
$1.000 \mathrm{~g} / \mathrm{kg}$ de MS) em substituição a silagem de Urochloa brizantha cv. Marandu. Estes autores observaram menores teores de FDA à medida que foram aumentando os teores de silagem de sorgo na ração, o que propiciou maior concentração energética as dietas com maiores níveis de silagem de sorgo.

Em relação à eficiência de proteína bruta e extrato etéreo, não houve diferença para os diferentes tipos de volumoso, em função da similaridade entre as dietas (Tabela 7). As eficiências das fibras em detergente neutro e ácido não variaram entre os tratamentos alimentares, sendo os valores médios de 0,269 $\mathrm{g}$ de peso vivo/kg de FDN e 0,724 $\mathrm{g}$ de peso vivo/kg de FDA, respectivamente.

Tabela 7. Eficiências protéica, energética, extrato etéreo e de fibras em detergente neutro e ácido de novilhos alimentados com diferentes tipos de volumoso.

\begin{tabular}{lcccc}
\hline \multirow{2}{*}{ Eficiências } & \multicolumn{2}{c}{ Tipos de Silagem } & \multirow{2}{*}{ Erro-padrão } & \multirow{2}{*}{ Probabilidade } \\
\cline { 2 - 3 } & Papuã & Sorgo & & \\
\hline Protéica, g de peso vivo/kg proteína bruta & 0,991 & 1,071 & 0,057 & 0,3664 \\
Energética, g de peso vivo/Mcal & 0,051 & 0,050 & 0,003 & 0,8816 \\
Extrato etéreo, g de peso vivo/kg de EE & 6,608 & 6,426 & 0,351 & 0,7291 \\
FDN $^{2}$, g de peso vivo/kg de FDN & 0,241 & 0,297 & 0,017 & 0,0691 \\
FDA $^{3}$, g de peso vivo/kg de FDA & 0,697 & 0,751 & 0,022 & 0,1423 \\
\hline
\end{tabular}

${ }^{1}$ Extrato Etéreo

${ }^{2}$ Fibra em detergente neutro

${ }^{3}$ Fibra em detergente ácido

Fonte: Elaboração dos autores.

Todavia, verifica-se na Tabela 8 , que os animais que consumiram silagem de papuã atingiram o peso ao abate pré-estabelecido de $430 \mathrm{~kg}$ em 170 dias, enquanto que os animais que consumiram silagem de sorgo atingiram o peso ao abate após 136 dias de confinamento. Dessa forma, além do desempenho, juntamente deve-se realizar uma análise mais criteriosa quanto aos custos operacionais envolvidos no processo de confinamento.
Avaliar o desempenho em função do tipo de volumoso é importante uma vez que estas características estão intimamente associadas à análise de custos. Dessa forma, ambos os tipos de volumoso promovem características semelhantes quanto ao ganho de peso, o capim papuã por ser uma invasora, não apresenta custos de implantação o que pode lhe conferir uma alternativa mais econômica de volumoso na dieta de bovinos. 
Tabela 8. Peso inicial e final, ganho médio diário, escores inicial e final, ganho total de escore corporal e conversão alimentar de novilhos alimentados com diferentes tipos de volumosos.

\begin{tabular}{|c|c|c|c|c|}
\hline \multirow{2}{*}{ Variáveis } & \multicolumn{2}{|c|}{ Tipos de Silagem } & \multirow{2}{*}{$\begin{array}{c}\text { Erro- } \\
\text { padrão }\end{array}$} & \multirow{2}{*}{ Probabilidade } \\
\hline & Papuã & Sorgo & & \\
\hline Peso Inicial, kg & 241,33 & 245,16 & 18,023 & 0,8863 \\
\hline Peso Final, kg & 453,33 & 432,00 & 21,241 & 0,5093 \\
\hline $\mathrm{GMD}^{1}, \mathrm{~kg} / \mathrm{dia}$ & 1,25 & 1,37 & 0,040 & 0,0759 \\
\hline $\mathrm{ECl}^{2}$, pontos ${ }^{*}$ & 2,16 & 2,18 & 0,049 & 0,8220 \\
\hline $\mathrm{ECF}^{3}$, pontos* & 4,08 & 4,02 & 0,050 & 0,3939 \\
\hline $\mathrm{GTEC}^{4}$, pontos/dia ${ }^{*}$ & 1,92 & 1,83 & 0,046 & 0,2586 \\
\hline $\mathrm{CA}^{5}, \mathrm{~kg} \mathrm{MS} / \mathrm{kg} \mathrm{PV}$ & 7,92 & 7,64 & 0,469 & 0,6851 \\
\hline $\mathrm{CA}^{6}, \mathrm{~g} / \mathrm{PV}^{0,75}$ & 98,94 & 96,75 & 2,349 & 0,5387 \\
\hline $\mathrm{CAPV}^{7}, \mathrm{~kg} / 100 \mathrm{~kg}$ de PV & 2,30 & 2,26 & 0,430 & 0,5373 \\
\hline
\end{tabular}

${ }^{1}$ GMD: Ganho Médio Diário

${ }^{2}$ ECI: Escore Corporal Inicial

${ }^{3}$ ECF: Escore Corporal Final

${ }^{4}$ GTEC: Ganho Total Escore Corporal

${ }^{5} \mathrm{CA}$ : conversão alimentar kg de matéria seca por kg de Peso Vivo

${ }^{6} \mathrm{CA}$ : Conversão Alimentar g por tamanho metabólico

${ }^{7} \mathrm{CAPV}$ : Conversão Alimentar kg por $100 \mathrm{~kg}$ de Peso Vivo

* Escala variando de 1 a 5 , onde 1 = muito magro e $5=$ muito gordo.

Fonte: Elaboração dos autores.

Gottschall et al. (2009), observaram que o ganho médio diário apresenta uma correlação negativa com o tempo de permanência dos animais em confinamento, ou seja, o aumento na taxa de ganho de peso gera redução no número de dias de confinamento. De acordo com Albright et al. (1993) a taxa de ganho de peso é um dos principais fatores que interferem no desempenho animal, afetando principalmente a eficiência do sistema de produção. Restle et al. (2003), trabalhando com bezerros com peso inicial de $159,5 \mathrm{~kg}$, constataram maior ganho de peso com a utilização da mistura silagem de milho mais sorgo em relação à silagem de capim papuã (1,061 contra $0,800 \mathrm{~kg} /$ dia $)$.

Os animais apresentavam no início do confinamento baixo estado corporal (2,17 pontos), classificando-os como magros. No entanto, os tratamentos alimentares promoveram boa deposição de gordura, de modo que o estado corporal final dos animais lhes classificaram como gordos (média de 4,05 pontos).

Observa-se que a conversão da MS nas diferentes formas de expressar não diferiu $(\mathrm{P}>0,05)$ entre os tratamentos, sendo os animais que consumiram silagem de papuã e silagem de sorgo, apresentaram valores de conversão alimentar de 7,92 e 7,64 kg de MS ingerida $/ \mathrm{kg}$ de ganho, respectivamente. Chizzotti et al. (2005), estudando o desempenho de novilhos Nelore recebendo dietas contendo diferentes proporções de silagens de Urochloa brizantha cv. Marandu e de Sorgo, constataram que a conversão alimentar não foi influenciada pela inclusão de silagem de sorgo nas dietas, registrando valor médio de $8,98 \mathrm{~kg}$ de MS ingerida/ $\mathrm{kg}$ de ganho.

\section{Conclusão}

O uso da silagem de capim papuã é uma alternativa viável na proporção volumoso:concentrado utilizada para substituir a silagem de sorgo na terminação de novilhos em confinamento.

\section{Agradecimentos}

Agradeço ao Conselho Nacional de 
Desenvolvimento Científico e Tecnológico, CNPq, pela bolsa concedida durante o mestrado.

\section{Referências}

ALBRIGHT, M. L.; LANGEMEIER, M. R.; MINTERT, J. R.; SCHROEDER, T. C. Factors affecting cattle feeding profitability and cost of gain. Kansas State University, Manhattan, 1993. p. 1-4. (Beef Cattle Handbook, BCH8050).

ANUALPEC. Anuário da pecuária brasileira. São Paulo: AgraFNP, 2010. 360 p.

ARAÚJO, G. G. L.; SILVA, J. F. C.; VALADARES FILHO, S. C.; CAMPOS, O. F.; CASTRO, A. C. G.; SIGNORETTI, R. D.; TURCO, S. H. N.; HENRIQUES, L. T. Consumo e digestibilidade total dos nutrientes de dietas contendo diferentes níveis de volumoso, em bezerros. Revista Brasileira de Zootecnia, Viçosa, MG, v. 27, n. 2, p. 345-354, 1998.

ASSOCIATION OF OFFICIAL ANALYTICAL CHEMISTRY - AOAC. Official methods of analysis. 16. ed. Washington, D.C., 1995. 2000 p.

BALCH, C. C.; CAMPLING, R. C. Regulation of voluntary food intake in ruminants. Nutrition Abstracts and Review, v. 32, n. 3, p. 669-686, 1962.

CABRAL, L. S.; VALADARES FILHO, S. C.; DETMANN,E.;MALAFAIA,P.A.M.;ZERVOUDAKIS, J. T.; SOUZA, A. L.; VELOSO, R. G.; NUNES, P. M. M. Consumo e digestibilidade dos nutrientes em bovinos alimentados com dietas à base de volumosos tropicais. Revista Brasileira de Zootecnia, Viçosa, MG, v. 35, n. 6, p. 2406-2412, 2006.

CHILIBROSTE, P.; TAMMINGA, S.; BOER, H.; GIBB, M. J.; DEN DIKKEN, G. Duration of regrowth of ryegrass (Lolium perenne) effects on grazing behaviour, intake, rumen fill and fermentation of lactating cows. Journal of Dairy Science, Madison, v. 83, n. 5, p. 984995, 2000.

CHIZZOTTI, F. H. M.; PEREIRA, O. G.; VALADARES FILHO, S. C.; GARCIA, R.; CHIZZOTTI, M. L.; LEÃO, M. I.; PEREIRA, D. H. Consumo, digestibilidade total e desempenho de novilhos Nelore recebendo dietas contendo diferentes proporções de silagens de Brachiaria brizantha cv. Marandu e de sorgo. Revista Brasileira de Zootecnia, Viçosa, MG, v. 34, n. 6, p. 2427-2436, 2005.

FORBES, J. M. Voluntary food intake and diet selection in farm animals. Walingford: CAB International, 1995. $532 \mathrm{p}$.

GOTTSCHALL, C. S.; CANELLAS, L. C.; MARQUES,
P. R.; BITTENCOURT, H. R. Relações entre idade, peso, ganho médio diário e tempo médio de permanência de novilhos de corte confinados para abate aos 15 ou 27 meses de idade. Semina: Ciências Agrárias, Londrina, v. 30, n. 3, p. 717-726, 2009.

HUSSEIN, H. S.; MERCHEN, N. R.; FAHEY JÚNIOR, G. C. Efects of forage level and canola seed supplementation on site and extent of digestion of organic matter, carbohydrates, and energy by steers. Journal of Animal Science, Champaign, v. 73, n. 8, p. 2458-2468, 1995.

ÍTAVO, L. C. V.; VALADARES FILHO, S. C.; SILVA, F. F.; VALADARES, R. F. D.; LEÃO, M. I.; CECON, P. R.; ÍTAVO, C. C. B. F.; MORAES, E. H. B. K.; PAULINO, P. V. R. Consumo e digestibilidades aparentes totais e parciais de nutrientes em novilhos alimentados com dietas contendo vários níveis de concentrado. Revista Brasileira de Zootecnia, Viçosa, MG, v. 31, n. 3, p. 15431552, 2002.

LICITRA, G.; HERNANDEZ, T. M.; VAN SOEST, P. J. Standartization of procedures for nitrogen fractionation of ruminant feeds. Animal Feed Science and Technology, Amsterdam, v. 57, n. 4, p. 347-358, 1996.

MADSEN, J.; HVELPUND, T.; WEISBJERG, M. R. Appropriate methods for the evaluation of tropical feeds for ruminants. Animal Feed Science and Technology, Amsterdam, v. 69, n. 1, p. 53-66, 1997.

MCDONALD, P. The biochemistry of silage. New York: John Willey \& Sons, 1981. 226 p.

MERTENS, D. R. Using neutral detergent fiber to formulate dairy rations. In: GEORGIA NUTRITION CONFERENCE FOR THE FEED INDUSTRY, 1982, Athens. Proceedings... Athens: University Georgia, 1982. p. 116-126.

Analysis of fiber in feeds and its use in feed evaluation and ration formulation. In: SIMPÓSIO INTERNACIONAL DE RUMINANTES, 1992, Lavras, MG. Proceedings... Lavras: Universidade Federal de Lavras, 1992. p. 1-33.

Regulation of forage intake. In: FAHEY

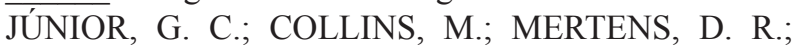
MOSER, L. E. (Ed.). Forage quality, evaluation and utilization. American Society of Agronomy, Crop Science of America, Soil Science of America, Madison, W.I. 1994. p. 450-493.

MOORE, J. E. Forage crops. In: HOVELAND, C. S. (Ed.). Crop quality, storage, and utilization. Madison: American Society: Crop Science Society of America, 1980. p. 61-91.

NATIONAL RESEARCH COUNCIL - NRC. Nutrient 
requirements of beef cattle. 7. ed. Washington, DC: NRC, 1996. 232 p.

PACHECO, P. S.; RESTLE, J.; VAZ, F. N.; FREITAS, A. K.; PADUA, J. T.; NEUMANN, M.; ARBOITTE, M. Z. Avaliação econômica da terminação em confinamento de novilhos jovens e superjovens de diferentes grupos genéticos. Revista Brasileira de Zootecnia, Viçosa, MG, v. 35, n. 1, p. 309-320, 2006.

RESTLE, J.; NEUMANN, M.; BRONDANI, I. L.; GONÇALVES, J. M.; PELLEGRINI, L. G. Avaliação da silagem de capim Papuã (Brachiaria plantaginea) por meio do desempenho de bezerros de corte confinados. Ciência Rural, Santa Maria, v. 33, n. 4, p. 749-756, 2003.

SENGER, C. C. D.; KOZLOSKI, G. V.; SANCHEZ, L. M. B.; MESQUITA, F. R.; ALVES, T. P.; CASTAGNINO,
D. S. Evaluation of autoclave procedures for fibre analysis in forage and concentrate feedstuffs. Animal Feed Science and Technology, Amsterdam, v. 146, n. 1-2, p. 169-174, 2008.

VAN SOEST, P. J. Nutritional ecology of the ruminant. 2. ed. Ithaca, New York: Cornell University Press, 1994. $476 \mathrm{p}$.

. Nutritional ecology of the ruminant. 2. ed. Ithaca: Cornell University Press, United States of America, 1991. $476 \mathrm{p}$.

WEISS, W. P.; CONRAD, H. R.; ST. PIERRE, N. R. A theoretically-based model for predicting total digestible nutrient values of forages and concentrates. Animal Feed Science and Technology, Amsterdam, v. 39, n. 1-2, p. 95$110,1992$. 